\title{
Single minimal incision fasciotomy for chronic exertional compartment syndrome of the lower leg
}

\author{
Nicola Maffulli ${ }^{1,2 *}$, Mattia Loppini ${ }^{3}$, Filippo Spiezia ${ }^{3}$, Alessio D’Addona $^{4}$ and Gayle D. Maffulli ${ }^{2}$
}

\begin{abstract}
Background: Chronic exertional compartment syndrome (CECS) involves a painful increase in compartment pressure caused by exercise and relieved by rest, common in athletes. The most common site for CECS in the lower limbs is the anterior leg compartment. The aim of this study is to evaluate the outcomes of a single minimal incision fasciotomy in athletes and their capability to return to high level sport activity.

Methods: The study reports mid-term results in a series of 18 consecutive athletes with chronic exertional compartment syndrome of the leg who had undergone minimally invasive fasciotomy. Between 2000 and 2007, we prospectively enrolled 18 consecutive athletes (12 males and six females, median age 27 years) with unilateral or bilateral chronic exertional compartment syndrome undergoing unilateral or bilateral minimally invasive fasciotomy. Clinical outcomes were assessed with Short-Form Health Survey-36 (SF-36) and European Quality of Life-5 Dimension (EQ-5D) scale. The ability to participate in sport before and after surgery and the time to return to training (RTT) and to sport (RTS) were recorded.
\end{abstract}

Results: The median follow-up after surgery was 36 months. Both questionnaires showed a statistically significant improvement $(P<0.0001)$ after surgery. At the time of the latest follow-up, 17 of 18 patients $(94 \%)$ had returned to pre-injury or higher levels of sport. Only one patient (6\%) returned to sport at lower levels than those of pre-injury status. The median time to return to training and to return to sport was 8 and 13 weeks, respectively. No severe complications or recurrence of the symptoms were recorded.

Conclusions: Minimally invasive fasciotomy is effective and safe for athletes suffering from unilateral or bilateral chronic exertional compartment syndrome of the anterior and lateral compartments of the leg with good results in the mid-term.

Keywords: Leg, Compartment syndrome, Exertional, Fasciotomy, Minimal invasive

\section{Background}

Chronic exertional compartment syndrome (CECS) of the leg is common in athletes. Repetitive movements may cause it, especially in running or endurance sport activities, impairing athletic performance $[1,2]$. The intramuscular pressure may increase during exercise, leading to pain to the affected compartment, up to

\footnotetext{
* Correspondence: n.maffulli@qmul.ac.uk

'Department of Musculoskeletal Disorders, Faculty of Medicine and Surgery, University of Salerno, Salerno, Italy

${ }^{2}$ Centre for Sports and Exercise Medicine, Barts and The London School of Medicine and Dentistry, Mile End Hospital, 275 Bancroft Road, London E1 4DG, England

Full list of author information is available at the end of the article
}

induce athletes to abandon any sport activity. Aetiologically, the muscle swelling, secondary to repetitive activities, and fascial tightness are mainly involved factors increasing the compartment pressure [3, 4]. Usually, pain disappears at rest, but the involved muscles may become ischemic $[1,5-8]$. Therefore, surgical fasciotomy, which implies the decompression of the involved muscular compartments to decrease the pressure, is the treatment of choice [3, 9-14]. In athletes, the anterior, the lateral and the deep posterior compartments of the leg are commonly affected; the superficial posterior compartment is more rarely involved $[2,15]$. 
Different surgical approaches may be undertaken, including open, endoscopic, and minimally invasive procedures $[2,10,12,15-20]$.

We report the mid-term results in a series of 18 consecutive athletes with chronic exertional compartment syndrome of the leg who had undergone minimally invasive fasciotomy of the leg.

\section{Methods}

All procedures were performed after the local Ethical Committee of the Faculty of Medicine and Surgery of the University of Salerno (CESa 01252009/Rev2) had approved them and after patients had given their written informed consent. All the authors declare that the procedures followed were in accordance with the ethical standards of the responsible committee on human experimentation (institutional and national) and with the Helsinki Declaration of 1975, as revised in 2000 and 2008.

During the period from 2001 to 2007 , we prospectively enrolled 18 consecutive athletes (12 males and six females) (median age 27 years; range from 18 to 35 years) who had undergone minimally invasive fasciotomy for management of leg pain secondary to chronic exertional compartment syndrome (Table 1). The condition was unilateral in nine of 18 patients, bilateral in nine patients. The sport activity was running in nine patients, ballet in four, soccer in two, badminton in one, and squash in two. The median duration of symptoms before surgery was 17 months (from 5 to 31 months).

All patients were tertiary referrals to the senior author with the following diagnosis: CECS in six, persistent swelling in five, peroneal muscle strain in four, and shin pain in three. All athletes had been managed previously for a median period of 4 months (range from 1 to 6 months) with conservative therapies, which consisted in changing training modalities (shoes, stretching, shoe inserts), or application of local injection of local anesthetics at the site of maximal tenderness.

The diagnosis of CECS was made on history and clinical examination in all instances. All patients referred pain over the anterior/antero-lateral aspect of the leg after a well-defined period of exercise, generally $20 \mathrm{~min}$ (from 15 to 30). Symptoms always resolved after rest, within several minutes. At clinical examination, no patients complained of tenderness of the tibial shaft or surrounding soft tissues. Plain radiographs were undertaken to exclude a tibial stress fracture and other bony disorders.

Table 1 Demographic details and clinical outcomes of the enrolled athletes

\begin{tabular}{|c|c|c|c|c|c|c|c|c|c|c|}
\hline \multirow[t]{3}{*}{ Athlete } & \multirow[t]{3}{*}{ Gender } & \multirow[t]{3}{*}{ Sport } & \multirow{3}{*}{$\begin{array}{l}\text { Affected } \\
\text { side }\end{array}$} & \multirow{3}{*}{$\begin{array}{l}\text { Affected } \\
\text { compartment }\end{array}$} & \multirow{3}{*}{$\begin{array}{l}\text { Pre-injury level } \\
\text { of sport }\end{array}$} & \multirow{3}{*}{$\begin{array}{l}\text { Post-surgery } \\
\text { level of sport }\end{array}$} & \multicolumn{4}{|l|}{ Scores } \\
\hline & & & & & & & \multicolumn{2}{|l|}{$E Q-5 D$} & \multicolumn{2}{|l|}{ SF-36 } \\
\hline & & & & & & & Pre-surgery & Post-surgery & Pre-surgery & Post-surgery \\
\hline 1 & $M$ & Soccer & $R+L$ & Ant & Semi-professional & Semi-professional & 51 & 90 & 52 & 86 \\
\hline 2 & M & Soccer & $\mathrm{R}$ & Ant & Semi-professional & Sunday league & 55 & 92 & 51 & 90 \\
\hline 3 & M & Running & $R+L$ & Ant + Lat & County & County & 60 & 95 & 58 & 92 \\
\hline 4 & M & Running & L & Ant + Lat & County & County & 58 & 90 & 54 & 91 \\
\hline 5 & M & Running & $R+L$ & Ant & County & County & 61 & 92 & 59 & 88 \\
\hline 6 & M & Running & $R+L$ & Ant & Recreational & Recreational & 59 & 91 & 51 & 94 \\
\hline 7 & M & Running & $R+L$ & Ant + Lat & County & County & 59 & 92 & 57 & 96 \\
\hline 8 & F & Running & $\mathrm{R}$ & Ant & County & County & 53 & 90 & 58 & 97 \\
\hline 9 & M & Running & $R+L$ & Ant & County & National & 60 & 92 & 60 & 88 \\
\hline 10 & M & Running & $\mathrm{R}$ & Ant + Lat & County & County & 64 & 91 & 52 & 90 \\
\hline 11 & M & Running & $R+L$ & Ant & Recreational & Recreational & 53 & 98 & 57 & 95 \\
\hline 12 & F & Ballet & $\mathrm{R}$ & Ant + Lat & Recreational & Recreational & 62 & 94 & 51 & 85 \\
\hline 13 & F & Ballet & L & Ant + Lat & Recreational & Recreational & 67 & 90 & 62 & 92 \\
\hline 14 & $\mathrm{~F}$ & Ballet & $\mathrm{R}$ & Ant + Lat & Recreational & Recreational & 66 & 89 & 55 & 91 \\
\hline 15 & F & Ballet & $R+L$ & Ant & Recreational & Recreational & 53 & 88 & 58 & 89 \\
\hline 16 & $M$ & Badminton & $\mathrm{R}$ & Ant & Recreational & County & 59 & 91 & 53 & 91 \\
\hline 17 & M & Squash & $R+L$ & Ant + Lat & Recreational & Recreational & 53 & 92 & 53 & 94 \\
\hline 18 & $\mathrm{~F}$ & Squash & L & Ant & Recreational & Recreational & 66 & 92 & 52 & 86 \\
\hline
\end{tabular}

In this table, gender, type of sport performed, affected side, affected compartment, pre- and post-injury level of sport, and results of scores are reported. All results of EQ-5D and SF-36 scores are improved after surgery

$R$ right, $L$ left, Ant anterior, Lat lateral, EQ-5D European Quality of Life-5 Dimensions, SF-36 Short-Form Health Survey-36 
The measures of the dynamic compartment pressure confirmed the diagnosis of CECS in all instances [21-24]. The intracompartmental pressure (ICP) of the anterior and lateral compartments was measured bilaterally, at rest and 1 min after exercise. Diagnostic criterion for CECS was a value of ICP $>28 \mathrm{mmHg}, 1 \mathrm{~min}$ after exercise [21]. In healthy legs, the median values of ICP were $13.6 \mathrm{mmHg}$ (from 5.2 to 26.5 ) at rest and $17.5 \mathrm{mmHg}$ (from 11 to 26.3), $1 \mathrm{~min}$ after exercise. In affected legs, the median values of ICP were $22.5 \mathrm{mmHg}$ (from 6 to 51) at rest and $44 \mathrm{mmHg}$ (from 28.4 to 122.7), $1 \mathrm{~min}$ after exercise.

\section{Clinical assessment}

The Short-Form Healthy Survey-36 (SF-36) [25] and the European Quality of Life-5 Dimension (EQ-5D) [26] scores were administered to all patients at baseline and postoperatively, 6 weeks after surgery. These are selfadministered rating systems assessing the overall health status, the physical and psychological function, with a final score ranging from 0 (lowest health status) to 100 (highest health status).

All patients were asked about participation to sport before surgery and at the last follow-up and the time they had taken to return to training (RTT) and to sport (RTS) [27].

At the last follow-up, the overall satisfaction of patients with surgery was evaluated according to a three-staged self-reported scoring system: none was a condition of minimal or no relief, moderate was significant relief, and good was return to full activity with minimal or no symptoms.

\section{Surgical technique}

The senior author performed all procedures as day cases. With the patients in supine position and the tourniquet inflated to the tight, the skin was prepared in the usual fashion, and sterile drapes were applied.

A $2.5-\mathrm{cm}$ vertical skin incision was performed over the anterior compartment, at the middle third of the leg, $1.0 \mathrm{~cm}$ lateral to the tibial crest. Once the fascia was identified, the skin was retracted, and subcutaneous tissues and layers down to the level of the fascia were carefully dissected with gloved fingers, proximally and distally. If required, to uncover the fascia, the blunt subcutaneous dissection was completed by pushing the closed scissors proximally and distally. In this way, when the deep fascia could be clearly visualized, it was incised with a knife, at an average distance of $1.0 \mathrm{~cm}$ from the intermuscular septum (Fig. 1). Under direct vision, the fascia of the anterior compartment was divided proximally and distally, with scissors (Figs. 2, 3, and 4). In the same way, when the lateral compartment was also affected, through the same incision, the skin was retracted posteriorly to expose the fascia of the lateral compartment, which was cut. The incision was closed with subcuticular Biosyn suture 3.0 (Tyco Healthcare, Cork, Ireland); steristrips (3M Health Care, St Paul, MN, USA) were applied for the stab incisions. A Mepore dressing (Molnlycke Health Care, Gothenburg, Sweden) was applied.

Postoperatively, patients were discharged the day of surgery. They were allowed to weight bear as comfortable with elbow crutches and to move the ankle and knee. Patients used crutches for 7 to 10 days after the operation. At 2 weeks, the wounds were inspected, and rehabilitation was started, with gradual return to walking, jogging, and agility training. Competitive training was allowed at 4 weeks, at least; competitive sport was recommended not before than 8 weeks.

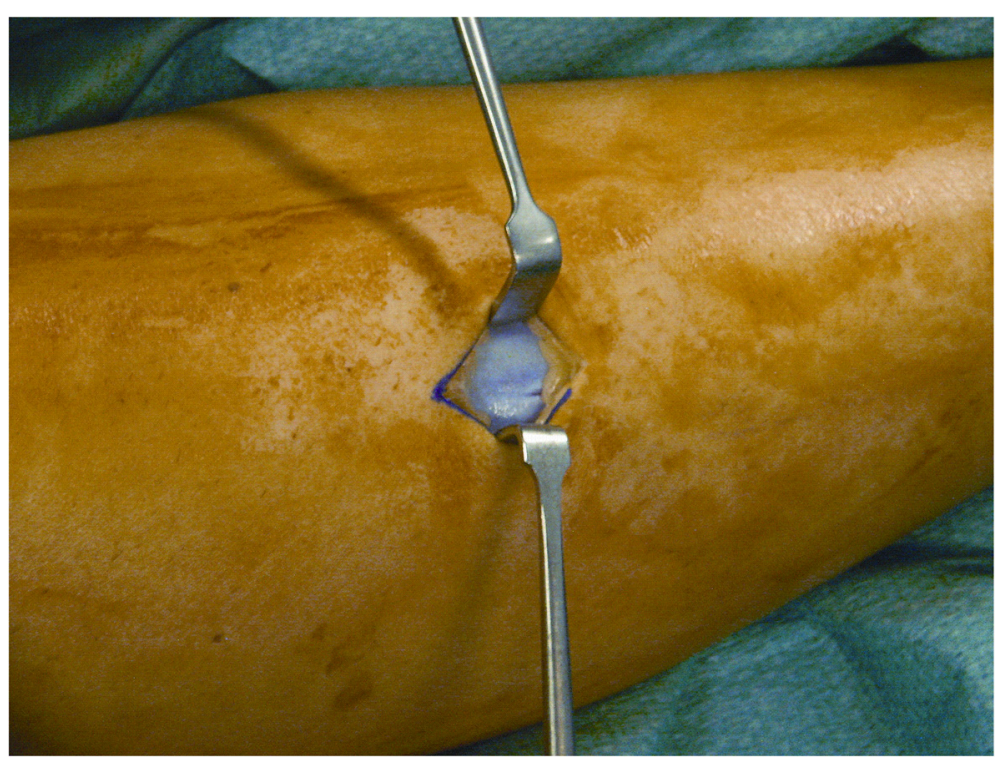

Fig. 1 Retraction of subcutaneous tissues and visualization of the deep fascia 


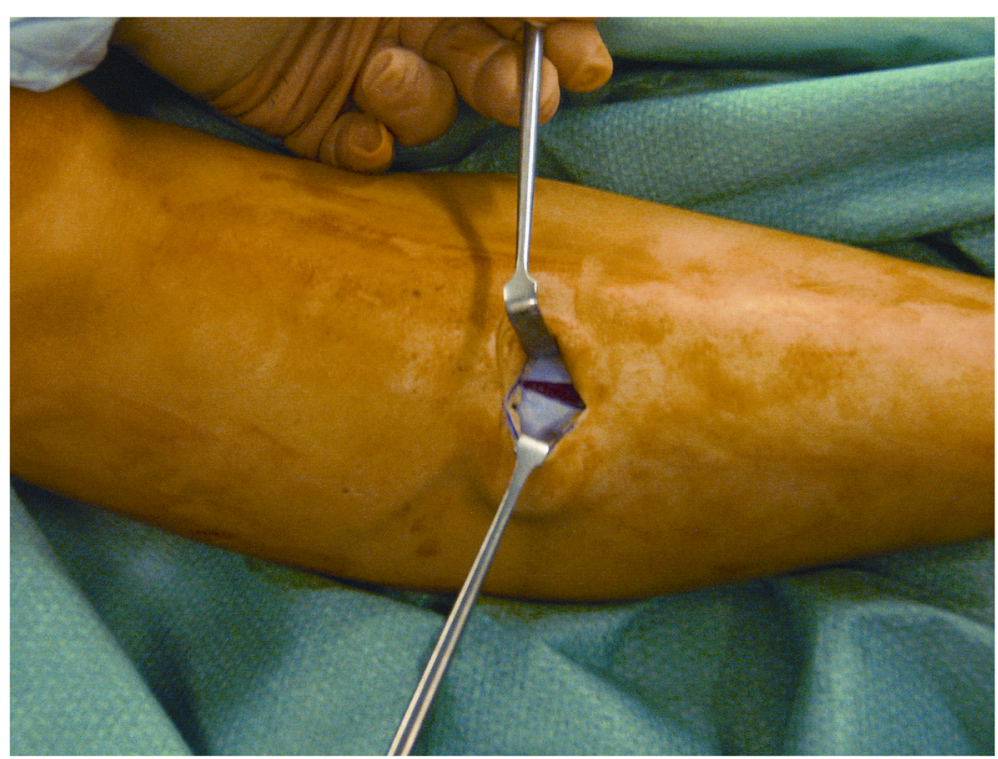

Fig. 2 Incision of the deep fascia

Clinical follow-ups were set at 2 and 6 weeks and 3, 6, and 12 months after surgery. Then, patients were examined once per year for a maximum of 4 years. The last follow-up was at a median time of 36 months (range from 26 to 50 months) after surgery.

\section{Data collection and statistical analysis}

Data were recorded in a computer database and analysed using SPSS for Mac (version 16.0). Demographic data, history, physical examination findings, and values of compartment pressure were recorded. Descriptive statistics was calculated. Wilcoxon signed-rank test was used to compare preoperative and postoperative EQ-5D and SF-36 scores. Pearson's chi-squared test with the Yates correction was used to assess the return to sport activity rate. Nonparametric statistical tests that were used as values were not found to be normally distributed. A $P$ value of $<0.05$ was considered significant.

\section{Results}

At the last follow-up, the median value of EQ-5D was increased from 59 (range from 51 to 67 ) at baseline to 92 (range from 88 to 98$)(P<0.0001)$; the median SF-36 from 55 (range from 51 to 62) at baseline to 91 (range

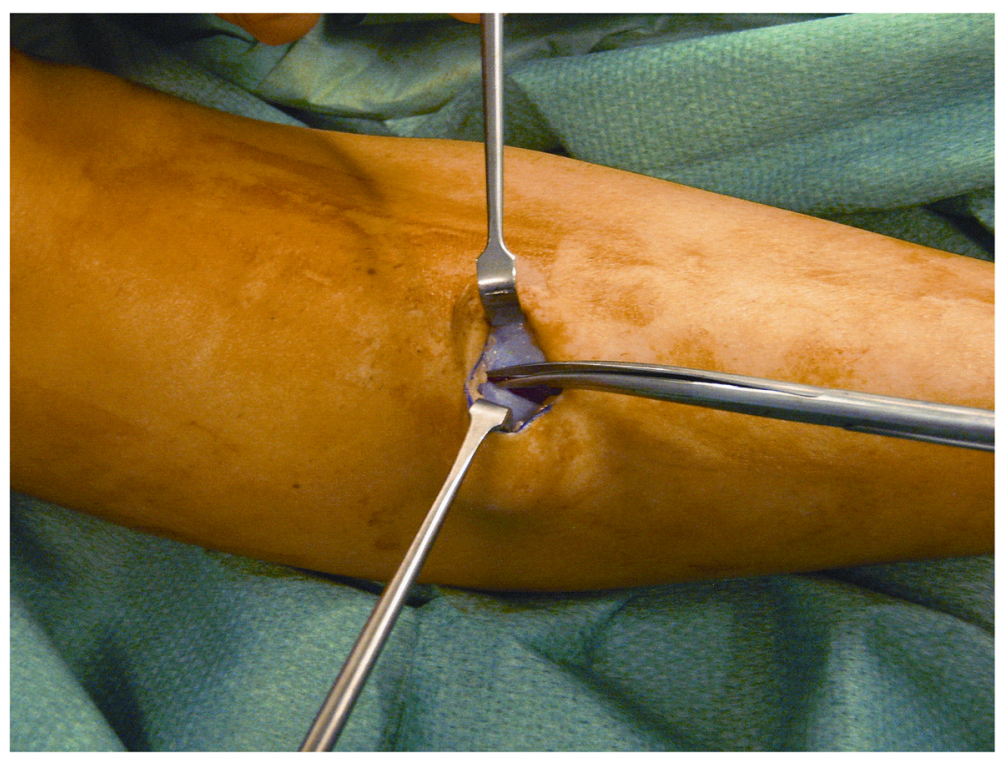

Fig. 3 Cranial division of the anterior and lateral compartment fascia 


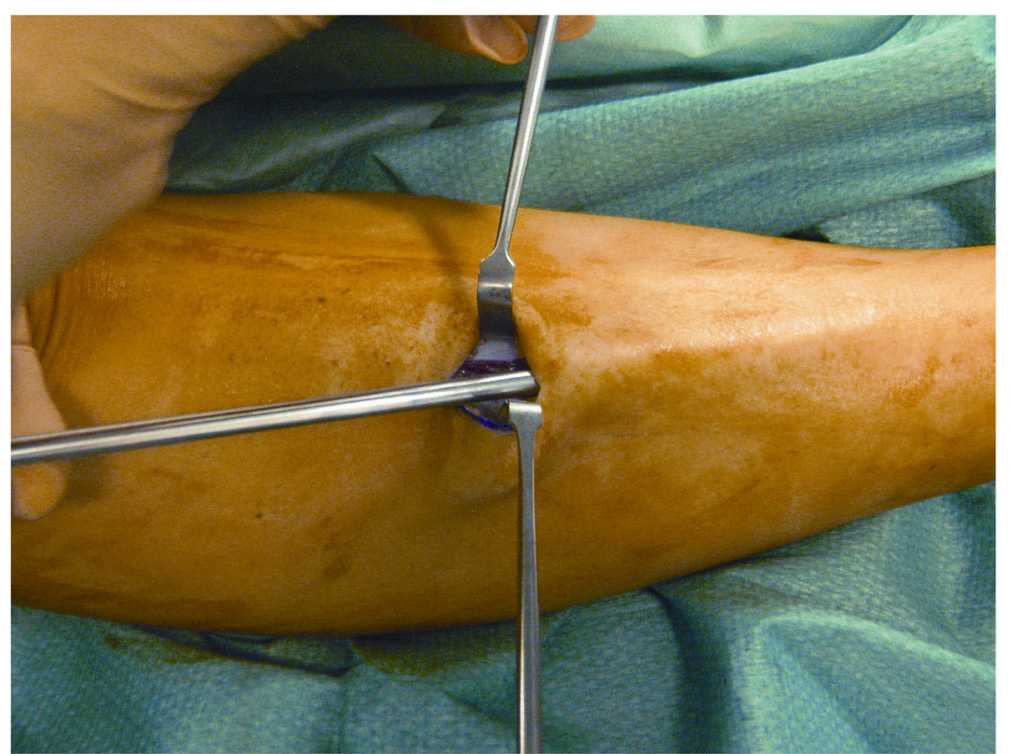

Fig. 4 Caudal division of the anterior and lateral compartment fascia

from 86 to 97$)(P<0.0001)$. Specifically, the median value of the mental component of SF-36 was 54 (range from 49 to 60) preoperatively and 92 (range from 86 to 97) postoperatively $(P<0.0001)$; the median value of the physical component of SF-36 was 56 (range from 52 to 62) preoperatively and 90 (range from 84 to 95 ) postoperatively $(P<0.0001)$.

Before surgery, 12 of 18 patients were unable to practise any sport activity, the remaining six patients could practise sport activity at lower levels. At the last followup, 15 of 18 patients had returned to pre-injury levels of sport, two had gained higher levels of competition compared to the pre-injury status, one had returned to sport at lower level. After surgery, there was a statistically significant increase of the number of patients able to perform sport at pre-injury or higher level (from 0 to $94 \%$; $P<0.0001$ ), and a statistically significant decrease of the number of patients fully unable to practise any sport (from 67 to $0 \% ; P<0.0001$ ) and those able to do sport at reduced levels (from 33 to $6 \%$; $P<0.0001$ ). The median time to return to competitive training was 8 weeks (range from 4 to 12); the median time to return to competitive sport was 13 weeks (range from 9 to 18). At the last follow-up, the overall satisfaction for the procedure was graded as good in 17 of 18 patients, moderate in one patient.

Of 27 fasciotomies performed (nine bilateral), we recorded two superficial wound infections, resolved with oral antibiotics, one hypertrophic scar, and one skin stretching around the scar. Numbness around the wound developed in one patient, and spontaneously resolved within 8 weeks after the index procedure. One patient complained of weakness in ankle dorsiflexion.
This event was managed with targeted physiotherapy, until the recovery was complete. No patients had recurrence of symptoms.

\section{Discussion}

The main finding of the present study is that this minimally invasive fasciotomy through a single incision is safe and effective for management of chronic exertional compartment syndrome of the leg, allowing patients to return quickly to sport activities, with high overall satisfaction in the mid-term. The efficacy of fasciotomy as standard management for patients with CECS of the leg is well known [3, 4, 9, 12, 13, 15, 17, 19]. In our series, we used a single incision minimally invasive fasciotomy in patients with anterior or antero-lateral CECS of the leg. At a median follow-up of 3 years, outcomes were surprisingly good compared to the baseline and stable.

Fascial release may be performed using one or two incisions [10,12, 15, 16, 18-20, 28, 29], three or more incisions in patients with long legs [3]. When performed endoscopically, the fascia may be visualized directly, using single or two incisions [30-32]. Nevertheless, the problem may recur, mostly if the release is incomplete. Some complications may also occur after fasciotomy: infections, haematoma, injury to the nerves and vessels, scars, fascial adhesions, swelling, lymphocele, and haemorrhage of the leg $[3,12,15,17]$. Specifically, as shown in cadavers, the peroneal nerve may be injured at the junction between the middle and the distal third of the calf, 10 to $12 \mathrm{~cm}$ proximally to the lateral malleolus, regardless of the technique used [30]. However, the risk of injury to the peroneal nerve is lower when undertaking an endoscopically assisted fascial release of the anterior 
and the lateral compartments through a single incision. In the short term, the overall rate of complications is $22 \%$. In our series, none of the patients experienced severe complications or recurrence of symptoms. Only one patient presented weak dorsiflexion of the ankle that regressed after tailored physiotherapy [20,33], and 2 of 11 patients who had undergone bilateral fasciotomy complained of leg weakness for an average of 3 months after surgery.

Our results were surprisingly encouraging, probably because all patients had anterior or antero-lateral CECS, which are reported to present better outcomes $[4,12$, $13,15,17,31]$ compared to compartment syndromes of the posterior compartment $[1,3,9,10,15,17,34]$. Mouhsine et al. [33] reported the long-term results of 18 athletes with anterior and/or lateral CECS of the leg, in whom the release of the fascia had been made through two minimal incisions, without tourniquet. The fact that patients had returned to sport activities at an average of 25 days after the index procedure, and all at the preinjury level of activity, confirms that the double incision technique allows to decompress completely the anterior and lateral compartments, without major risks [12]. We also reported a good result, using a single incision. Our technique has some features in common with that performed by Mouhsine et al. [33]. First of all, the release of the skin and subcutaneous tissues allows to decompress the compartments under direct control. We also have used the gloved finger to perform a blunt dissection. The single incision technique may appear to be more technically demanding, but it allows complete decompression of the compartment by advancing the scissors subcutaneously, proximally, and distally. A small skin incision could not allow to release completely the fascia, as the wound edges can hinder the blades of the scissors. For this reason, we use long scissors, cutting the fascia at a remarkably long distance from the skin incision. Moreover, the fact that the branches of the scissors have not to be widely opened, it prevents any potential damage to the overlying skin. Finally, the surgeon may appreciate the consistence and resistance of the fascia released during the procedure, having care that the tip of the scissors is open. This makes it possible to assume that the fasciotomy is complete when the resistance cannot be appreciated anymore. We encourage early mobilization and weight-bearing to prevent scarring and adhesions [9, 12, 34], even though most patients may not weight bear immediately after the operation because of the pain. Thus, we recommend patients to weight bear as they are comfortable.

In the study by Mouhsine et al. [33], symptoms persisted less than 7 months; in our patients, the duration of symptoms was longer, probably in relation to the fact that our unit care is a tertiary referral centre. We are aware that a prolonged duration of symptoms (>12 months) from the first occurrence is a negative prognostic factor [33], but this was not observed in our study.

We well acknowledge that there are many procedures to perform fasciotomy but, to the best of our knowledge, this is the first study to describe a minimally invasive fasciotomy through a single minimal incision of both anterior and lateral compartments. Strengths of the study are its prospective nature, the fact that a single fully trained surgeon performed all the operations without any surgical-associated procedure, the patients were included according to strict selection criteria, and no patient was lost to the follow-up. Moreover, an independent reviewer not involved at surgery assessed the outcomes at the follow-ups. A critical point is that the postoperative program used in the study could not be the most appropriate, but it was uniform throughout the study. In spite of this, we now point that, ideally, the rehabilitation should be standardized in all the studies.

A major limitation of the study is the lack of a control group of patients, making it impossible to prove whether this procedure is superior to the previous techniques used for management of anterior and/or lateral CECS. We are aware that our evidence is not strong as that of randomized controlled trials but, in referral to the low frequency of this injury, these latter studies would likely be too long and costly to be performed. Nevertheless, given the results, our approach should be taken into account as management of these patients. Another limitation is represented by the outcome measures used. We acknowledge that the SF-36 and EQ-5D scores are generic tools of assessment of the health status, and that a disease-specific questionnaire should be used, but no scoring systems specific for CECS have been described yet.

\section{Conclusions}

In conclusion, although this approach could appear technically demanding, it is safe and allows most of patients to recover completely and return to pre-injury sport levels of activity, with good overall satisfaction and physical function in the mid-term. Therefore, it may be considered as an alternative to traditional open surgery.

\section{Consent to publish}

We have obtained consent to publish from the participants.

\section{Abbreviations}

CECS: chronic exertional compartment syndrome; EQ-5D: European Quality of Life-5 Dimensions; ICP: intracompartmental pressure; RTS: return to sport RTT: return to training; SF-36: Short-Form Health Survey-36.

\section{Competing interests}

We confirm that we have read BioMed Central's guidance on competing interests. NM is the Editor-in-Chief for Journal of Orthopaedic Surgery and Research. The authors' declare that they have no competing interests. 


\section{Authors' contributions}

NM conceived the study, collected data, and analysed them. He wrote the first draft of the manuscript and operated on all the patients. ML helped in setting up the study, interpreted the data, and wrote the manuscript. FS collected data and analysed them. He helped to write the first draft of the manuscript. AD'A helped in setting up the study and helped in the analysis and interpretation of the data. GM helped in setting the study up and in data collection. She helped in writing the first draft of the manuscript. All authors read and approved the final manuscript.

\section{Author details}

'Department of Musculoskeletal Disorders, Faculty of Medicine and Surgery, University of Salerno, Salerno, Italy. ${ }^{2}$ Centre for Sports and Exercise Medicine, Barts and The London School of Medicine and Dentistry, Mile End Hospital, 275 Bancroft Road, London E1 4DG, England. ${ }^{3}$ Department of Orthopaedic and Trauma Surgery, Campus Biomedico University, Via Alvaro del Portillo, 200, 00128 Trigoria, Rome, Italy. ${ }^{4}$ Department of Public Health, Section of Orthopaedic and Trauma Surgery, University of Naples "Federico II", School of Medicine and Surgery, Naples, Italy.

Received: 9 October 2015 Accepted: 24 April 2016

Published online: 24 May 2016

\section{References}

1. Allen MJ, Barnes MR. Exercise pain in the lower leg. Chronic compartment syndrome and medial tibial syndrome. J Bone Joint Surg Br. 1986;68:818-23.

2. Balduini FC, Shenton DW, O'Connor KH, Heppenstall RB. Chronic exertional compartment syndrome: correlation of compartment pressure and muscle ischemia utilizing 31P-NMR spectroscopy. Clin Sports Med. 1993;12:151-65.

3. Detmer DE, Sharpe K, Sufit RL, Girdley FM. Chronic compartment syndrome: diagnosis, management, and outcomes. Am J Sports Med. 1985;13:162-70.

4. Qvarfordt P, Christenson JT, Eklof B, Ohlin P, Saltin B. Intramuscular pressure, muscle blood flow, and skeletal muscle metabolism in chronic anterior tibial compartment syndrome. Clin Orthop Relat Res. 1983;179:284-90.

5. Styf J, Forssblad P, Lundborg G. Chronic compartment syndrome in the first dorsal interosseous muscle. J Hand Surg Am. 1987;12:757-62.

6. Styf J, Korner L, Suurkula M. Intramuscular pressure and muscle blood flow during exercise in chronic compartment syndrome. J Bone Joint Surg Br. 1987;69:301-5.

7. Styf J, Lysell E. Chronic compartment syndrome in the erector spinae muscle. Spine (Phila Pa 1976). 1987;12:680-2.

8. Styf JR, Korner LM. Diagnosis of chronic anterior compartment syndrome in the lower leg. Acta Orthop Scand. 1987;58:139-44.

9. Bell S. Repeat compartment decompression with partial fasciectomy. J Bone Joint Surg Br. 1986;68:815-7.

10. Blackman PG. A review of chronic exertional compartment syndrome in the lower leg. Med Sci Sports Exerc. 2000;32:S4-10.

11. Puranen J, Alavaikko A. Intracompartmental pressure increase on exertion in patients with chronic compartment syndrome in the leg. J Bone Joint Surg Am. 1981;63:1304-9.

12. Rorabeck $\mathrm{CH}$, Bourne RB, Fowler PJ. The surgical treatment of exertional compartment syndrome in athletes. J Bone Joint Surg Am. 1983;65:1245-51.

13. Schepsis AA, Martini D, Corbett M. Surgical management of exertional compartment syndrome of the lower leg. Long-term followup. Am J Sports Med. 1993;21:811-7.

14. Wallensten R, Eriksson E. Intramuscular pressures in exercise-induced lower leg pain. Int J Sports Med. 1984;5:31-5.

15. Howard JL, Mohtadi NG, Wiley JP. Evaluation of outcomes in patients following surgical treatment of chronic exertional compartment syndrome in the leg. Clin Sports Med. 2000;10:176-84.

16. Bramante C, Gandolfo L, Bosco V. Minimally invasive fasciotomy in the treatment of chronic exertional anterior compartment syndrome of the leg: personal technique. Chir Ital. 2008;60:711-5.

17. Cook S, Bruce G. Fasciotomy for chronic compartment syndrome in the lower limb. ANZ J Surg. 2002;72:720-3.

18. de Fijter WM, Scheltinga MR, Luiting MG. Minimally invasive fasciotomy in chronic exertional compartment syndrome and fascial hernias of the anterior lower leg: short- and long-term results. Mil Med. 2006;171:399-403.

19. Martens MA, Backaert M, Vermaut G, Mulier JC. Chronic leg pain in athletes due to a recurrent compartment syndrome. Am J Sports Med. 1984;12:148-51.
20. Slimmon D, Bennell K, Brukner P, Crossley K, Bell SN. Long-term outcome of fasciotomy with partial fasciectomy for chronic exertional compartment syndrome of the lower leg. Am J Sports Med. 2002;30:581-8.

21. Aweid O, Del Buono A, Malliaras P, labal H, Morrissey D, Maffulli N, et al. Systematic review and recommendations for intracompartmental pressure monitoring in diagnosing chronic exertional compartment syndrome of the leg. Clin Sports Med. 2012;22:356-70.

22. Padhiar N, Allen M, King JB. Chronic exertional compartment syndrome of the foot. Sports Med Arthrosc. 2009;17:198-202.

23. Tsintzas D, Ghosh S, Maffulli N, King JB, Padhiar N. The effect of ankle position on intracompartmental pressures of the leg. Acta Orthop Traumatol Turc. 2009;43:42-8.

24. Tzortziou V, Maffulli N, Padhiar N. Diagnosis and management of chronic exertional compartment syndrome (CECS) in the United Kingdom. Clin Sports Med. 2006:16:209-13.

25. Ware JE. SF-36 health survey update. Spine (Phila Pa 1976). 2000;25:3130-9.

26. Brooks R. EuroQol: the current state of play. Health Policy. 1996;37:53-72.

27. Saxena A. Return to athletic activity after foot and ankle surgery: a preliminary report on select procedures. J Foot Ankle Surg. 2000;39:114-9.

28. Reneman RS. The anterior and the lateral compartmental syndrome of the leg due to intensive use of muscles. Clin Orthop Relat Res. 1975;113:69-80.

29. Turnipseed W, Detmer DE, Girdley F. Chronic compartment syndrome. An unusual cause for claudication. Ann Surg. 1989;210:557-63.

30. Hutchinson MR, Bederka B, Kopplin M. Anatomic structures at risk during minimal-incision endoscopically assisted fascial compartment releases in the leg. Am J Sports Med. 2003;31:764-9.

31. Leversedge FJ, Casey PJ, Seiler JG, Xerogeanes JW. Endoscopically assisted fasciotomy: description of technique and in vitro assessment of lower-leg compartment decompression. Am J Sports Med. 2002;30:272-8.

32. Ota $Y$, Senda M, Hashizume $H$, Inoue $H$. Chronic compartment syndrome of the lower leg: a new diagnostic method using near-infrared spectroscopy and a new technique of endoscopic fasciotomy. Arthroscopy. 1999;15:439-43.

33. Mouhsine E, Garofalo R, Moretti B, Gremion G, Akiki A. Two minimal incision fasciotomy for chronic exertional compartment syndrome of the lower leg. Knee Surg Sports Traumatol Arthrosc. 2006;14:193-7.

34. Black KP, Schultz TK, Cheung NL. Compartment syndromes in athletes. Clin Sports Med. 1990:9:471-87.

\section{Submit your next manuscript to BioMed Central and we will help you at every step:}

- We accept pre-submission inquiries

- Our selector tool helps you to find the most relevant journal

- We provide round the clock customer support

- Convenient online submission

- Thorough peer review

- Inclusion in PubMed and all major indexing services

- Maximum visibility for your research

Submit your manuscript at www.biomedcentral.com/submit
C Biomed Central 